\title{
Effects of Positioning on Cough Peak Flow and Muscular Electromyographic Activation in Duchenne Muscular Dystrophy
}

\author{
Layana Marques, Guilherme Augusto de Freitas Fregonezi, Ilsa Priscila Santos, \\ Ana Aline Marcelino, Jéssica Danielle Medeiros da Fonsêca, \\ Mario Emílio Teixeira Dourado-Júnior, Andrea Aliverti, \\ Antonio Sarmento, and Vanessa Regiane Resqueti
}

\begin{abstract}
BACKGROUND: Advanced stages of Duchenne muscular dystrophy (DMD) result in muscle weakness and the inability to generate an effective cough. Several factors influence the effectiveness of cough in patients with DMD. The aim of this study was to assess whether differences in positioning affect cough peak flow (CPF) and muscular electromyographic activation in subjects with DMD compared with paired healthy subjects. METHODS: Optoelectronic plethysmography and surface electromyography were used to assess chest wall volumes, chest wall inspiratory capacity, CPF, breathing pattern, and electromyographic activity of sternocleidomastoid, scalene, rectus abdominis, and external oblique muscles during inspiratory and expiratory cough phases in the supine position, supine position with headrest raised at $45^{\circ}$, and sitting with back support at $80^{\circ}$ in 12 subjects with DMD and 12 healthy subjects. RESULTS: Subjects with DMD had lower CPF $(P<.01)$ in comparison to control subjects in all positions; the DMD group also exhibited lower CPF $(P=.045)$ in the supine position versus $80^{\circ}$. Moreover, the relative volume contributions of the rib cage and abdominal compartments to tidal volume modified significantly with posture. The electromyographic activity during inspiratory and expiratory cough phases was lower in subjects with DMD compared to healthy subjects for all evaluated muscles $(P<.05)$, but no significant differences were observed with posture change. CONCLUSIONS: In subjects with DMD, posture influenced CPF and the relative contribution of the rib cage and abdominal compartments to tidal volume. However, muscular electromyographic activation was not influenced by posture in subjects with DMD and healthy subjects. Key words: Duchenne muscular dystrophy; cough; plethysmography; respiratory muscles; electromyography. [Respir Care 2020;65(11):1668-1677. (c) 2020 Daedalus Enterprises]
\end{abstract}

\section{Introduction}

Duchenne muscular dystrophy (DMD) is an X-linked neuromuscular disease resulting in progressive weakness

\footnotetext{
Drs de Freitas Fregonezi, Sarmento, and Resqueti, and Ms Marques, Ms Santos, Ms Marcelino, and Ms da Fonsêca are affiliated with the PneumoCardioVascular Lab, Hospital Universitario Onofe Lopes, Empresa Brasileira de Serviços Hospitalares, Natal, Brazil. Drs de Freitas Fregonezi, Sarmento, and Resqueti, and Ms Marques, Ms Santos, Ms Marcelino, and Ms da Fonsêca are affiliated with the Laboratório de Inovação Tecnológica em Reabilitação, Departamento de Fisioterapia, Universidade Federal do Rio Grande do Norte, Natal, Brazil. Dr Dourado-Júnior is affiliated with the Ambulatório de Neurologia, Empresa Brasileira de Serviços Hospitalares (EBSERH), Universidade Federal do Rio Grande do Norte, Natal, Brazil. Dr Aliverti is affiliated
}

and wasting of all the striated muscles, including the respiratory muscles, with an incidence of one in 3,500 live male births. ${ }^{1,2}$ Up to now, respiratory problems in DMD have been described mainly in terms of reduction of vital

\footnotetext{
with the Laboratorio di Tecnologie Biomediche, Dipartimento di Elettronica, Informazione e Bioingegneria, Politecnico di Milano, Milan, Italy.

Dr de Freitas Fregonezi prsented a version of this paper at the ALAT Congress, held June 27-30, 2018, in Mexico City, Mexico.

This study were financed in part by the Coordenação de Aperfeiçoamento de Pessoal de Nível Superior Brasil (CAPES) Finance Code 001 and Project PROCAD CAPES 2013 number 88881.068409/2014-01. Vanessa Regiane Resqueti is a fellow of the Conselho Nacional de Desenvolvimento Científico e Tecnológico $(\mathrm{CNPq})$ - process number
} 


\section{EFFECTS OF Positioning IN DMD}

capacity and inspiratory muscle weakness. In DMD, the linear decline of FVC expressed as a percentage of the predicted values through the years indicates progressive respiratory muscle weakness. ${ }^{3,4}$

With the progression of the disease and worsening of respiratory muscles function, cough, whose function is to maintain airway clearance and pulmonary hygiene, becomes critical. ${ }^{5-7}$ In DMD, ineffective cough leads to severe respiratory complications, such as ineffective airway clearance, pneumonia, atelectasis, and intubations. ${ }^{5}$ Several factors may lead to ineffective coughing, such as structural changes of the chest wall, reduced precough inspiratory volume, and respiratory muscle weakness. ${ }^{8-10}$ This weakness prevents the patient from taking a deep breath, decreasing the volume during the expiratory coughing phase, with aggravation in the presence of expiratory musculature impairment. ${ }^{9,11,12}$

Positioning leads to changes in thoracoabdominal kinematics during quiet spontaneous breathing in individuals with DMD. ${ }^{4,13}$ With the advancement of the disease, there is a significant and progressive reduction of the abdominal contribution to quiet spontaneous breathing while supine. According to LoMauro et al, ${ }^{4}$ the chest wall motion during spontaneous breathing is an important indicator of the degree of respiratory muscle impairment. However, the behavior of respiratory muscle activation during coughing in different positions is still unknown in patients with DMD as well as its influence on cough peak flow (CPF). The objective of this study was to assess whether differences in positioning affect $\mathrm{CPF}$ and muscular electromyographic activation in subjects with DMD compared with age-matched healthy subjects. We hypothesized that the positioning would influence muscular electromyographic activation and CPF generation, which would be stronger when the torso was more erect due to changes in the thoracoabdominal kinematics and muscular activation.

\section{Methods}

\section{Subjects and Inclusion Criteria}

This cross-sectional study was carried out according to the guidelines of the Helsinki Declaration and was

\footnotetext{
315580/2018-6. Guilherme Augusto de Freitas Fregonezi is fellow of the Conselho Nacional de Desenvolvimento Científico e Tecnológico (CNPq) - process number 312876/2018-1.
}

Supplementary material related to this paper is available at http://www. rcjournal.com.

Correspondence: Vanessa Regiane Resqueti PhD, Departamento de Fisioterapia, Universidade Federal do Rio Grande do Norte, Campus Universitário Lagoa Nova, Caixa Postal 1524, CEP 59072-970, Natal, Rio Grande do Norte, Brazil. E-mail: vanessaresqueti@hotmail.com.

DOI: $10.4187 /$ respcare. 07426

\section{QUICK LOOK}

\section{Current knowledge}

In patients with Duchenne muscular dystrophy, breathing patterns and kinematics of the chest wall are influenced by age and disease during spontaneous breathing with a predominance of the thoracic compartment over the abdominal in the supine position. Optoelectronic plethysmography allows a real-time assessment of a natural cough and chest wall volumes and avoids interference in the regular breathing pattern.

\section{What this paper contributes to our knowledge}

The cough peak flow is influenced by positioning in individuals with Duchenne muscular dystrophy. Respiratory muscle activation is not affected by different positions. The study also reveals that this population presented lower values of cough peak flow and muscle activation compared to control subjects. In addition, muscular activation must be taken into account when monitoring disease progression.

approved by the Research Ethics Committee of the University Hospital Onofre Lopes. All children in the study (when possible) and the legal guardian of each child signed the free, informed consent after explanation of all procedures, as proposed and approved by the institution's Commission of Ethics and Research.

The DMD group consisted of 12 subjects $>7$ y old with a confirmed clinical diagnosis of DMD evaluated by a neurologist based on traditional diagnostic criteria: progressive muscular deficit resulting in severe motor disability; increased muscle plasma enzymes; muscle biopsy identifying muscular degeneration and absence of dystrophin; alterations in the DMD gene (eg, deletions, duplications, or point mutations), ${ }^{14}$ with no associated infectious pulmonary diseases, no tracheostomy, and no use of sedatives or noninvasive ventilation for $>16 \mathrm{~h} / \mathrm{d}$. Subjects with DMD who did not complete the evaluation or were unable to adhere to the study protocol were excluded. The control group consisted of 12 male subjects paired according to age who reported themselves to be healthy without any history of cardiovascular, restrictive, or obstructive pulmonary disease. Subjects who presented values $<80 \%$ of predicted $\mathrm{FVC}$ or $\mathrm{FEV}_{1}$, as well as those who failed to perform the study protocol, were excluded.

\section{Pulmonary Function}

Pulmonary function was assessed using a KoKo DigiDoser spirometer (nSpire Health, Longmont, Colorado) according to the protocol recommended by the American 
Thoracic Society/European Respiratory Society. ${ }^{15}$ The predicted values were calculated as described by Quanjer et al. ${ }^{16}$ The highest values of each test were included in the statistical analysis.

\section{Respiratory Muscle Strength}

Respiratory muscle strength was evaluated using a digital manometer (NEPEB-LabCare, Belo Horizonte, Brazil) to measure maximum inspiratory and expiratory pressures from residual volume and total lung capacity, respectively (see supplementary materials at http://www.rcjournal. com). ${ }^{15,17}$ The sniff nasal inspiratory pressure test also evaluated inspiratory muscle strength. The predicted values for all respiratory muscle strength assessments were calculated using the reference values proposed for individuals $7-18$ y old and for individuals $>18$ y old. ${ }^{18-21}$ The highest values of each test were included in the statistical analysis.

\section{Chest Wall and Compartmental Volumes and Cough Peak Flow}

An optoelectronic plethysmography (OEP) system (BTS Bioengineering, Milan, Italy) was used to assess total chest wall and compartmental (ie, pulmonary rib cage, abdominal rib cage, and abdomen) volumes, breathing pattern, and $\mathrm{CPF}^{22,23}$ The measurement of CPF with OEP is a validated method. ${ }^{10,24-26}$ The analyses were carried out with each subject positioned in a hard bed in the supine position $\left(180^{\circ}\right)$, the supine position with headrest raised at $45^{\circ}$, sitting with back support at $80^{\circ}\left(80^{\circ}\right)$, and seated without back support due to muscle weakness. To calculate the volume changes of the posterior part of the trunk (hidden by the bed support), a virtual plane was defined and obtained by calculating a reference plane with the coordinates of the markers positioned laterally on the trunk of the individuals. ${ }^{27}$

For this study, the pulmonary rib cage and the abdominal rib cage compartments were considered as a single compartment (ie, rib cage), given by their sum. ${ }^{28-31}$ The analyses of the following variables were performed based on data obtained from the OEP: CPF derived from the displacement of the chest wall volume over time during coughing ${ }^{28-31}$; inspiratory capacity of the chest wall, the rib cage, and the abdomen during cough; the percentage of contribution of the rib cage and abdomen to the inspiratory capacity; volume of expired air from the chest wall during coughing; change in chest wall tidal volume and its compartments (ie, rib cage and abdomen); the percentage of contribution of the compartments to the change in tidal volume (ie, rib cage and abdomen); inspiratory time $\left(\mathrm{T}_{\mathrm{I}}\right)$, expiratory time $\left(\mathrm{T}_{\mathrm{E}}\right)$, and total respiratory cycle time $\left(\mathrm{T}_{\text {tot }}\right)$; the percentage of inspiratory time in relation to total time $\left(\mathrm{T}_{\mathrm{I}} / \mathrm{T}_{\text {tot }}\right)$; breathing frequency (f); expiratory minute volume $\left(\dot{\mathrm{V}}_{\mathrm{E}}\right)$; and the rapid shallow breathing index (RSBI), calculated as $\mathrm{f} / \mathrm{V}_{\mathrm{T}}{ }^{32}$

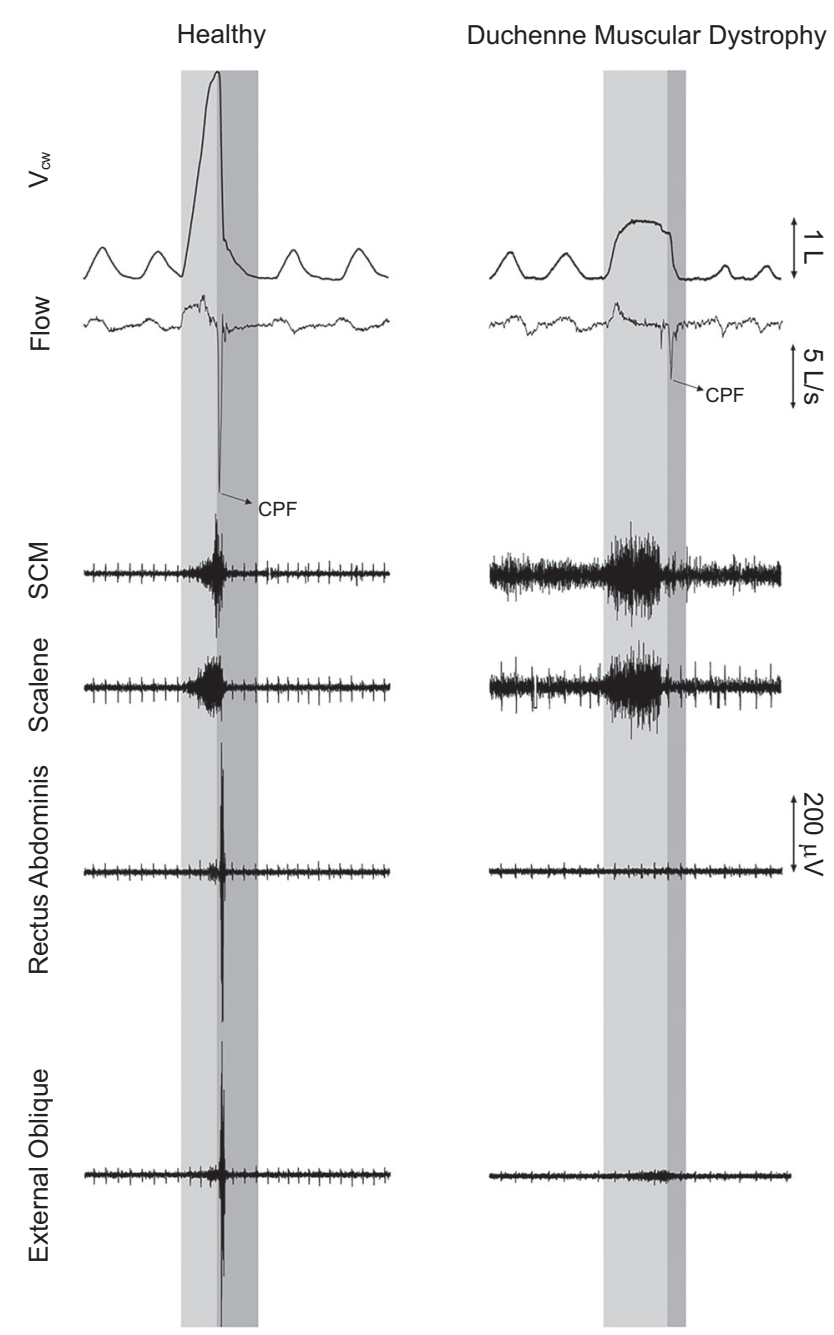

Fig. 1. Representative tracings of chest wall volume $\left(\mathrm{V}_{\mathrm{CW}}\right)$, flow, and raw SCM, scalene, rectus abdominis and external oblique muscles in one healthy subject and one Duchenne muscular dystrophy subject during a cough maneuver. CPF = cough peak flow; $V_{\mathrm{CW}}=$ chest wall volume; $\mathrm{SCM}=$ signals of the sternocleidomastoid.

\section{Electromyographic Recordings}

A TeleMyo DTS Desk Receiver electromyograph was used with 4 wireless Clinical DTS sensors (Noraxon USA, Scottsdale, Arizona) for surface electromyographic signal acquisition and processing. Signal acquisition was performed at a sampling frequency of $1,500 \mathrm{~Hz}$ with a 500 $\mathrm{Hz}$ low-pass filter, a gain of 1,000 times, and a common mode rejection index $>120 \mathrm{~dB}$. All data were analyzed using MR 3.8 software (Noraxon USA, Scottsdale, Arizona). Electromyographic data acquisition was performed synchronously with OEP (Fig. 1).

The passive bipolar surface electrodes were set according to SENIAM ${ }^{33}$ recommendations on the following muscles: sternocleidomastoid, in the lower third of the 


\section{EFFECTS OF Positioning IN DMD}

distance between the mastoid process and the sternoclavicular joint ${ }^{34}$; scalene, at $5 \mathrm{~cm}$ from the sternoclavicular joint and $2 \mathrm{~cm}$ above this point ${ }^{35}$; rectus abdominis at $4 \mathrm{~cm}$ from the umbilical $\mathrm{scar}^{34}$; and external oblique, at $50 \%$ of the upper anterior iliac spine line and the tip of the eleventh rib. ${ }^{35}$ All electrodes were placed on the right side of the body to reduce cardiac signal noises. The electromyographic signals were standardized as a percentage of root mean square. The signal was processed by applying the 20$\mathrm{Hz}$ high-pass filter, full wave rectification, smoothing with the root mean square algorithm and a 50-ms window, and a $30-\mathrm{Hz}$ Butterworth high-pass filter. All signals were normalized from the average of 3 maximum voluntary isometric contractions for the sternocleidomastoid, scalene, rectus abdominis, and external oblique; values were standardized as being equal to $100 \% .^{34-36}$

The fold change of the muscles during the inspiratory and expiratory phases was calculated by subtracting the normalized activation value of the evaluated muscle in spontaneous breathing (B) from the normalized muscle activation value in the evaluated cough stage (A) (ie, inspiratory or expiratory) in the same position divided by (B): fold change $=(\mathrm{A}-\mathrm{B}) / \mathrm{B}$. This calculation indicates the number of times the electromyographic signal increased or decreased from baseline.

\section{Functional Scale}

The Motor Function Measurement scale ${ }^{37}$ was used to assess functionality in subjects with DMD. This scale consisted of 32 items divided into 3 dimensions: standing position and transfers (13 items), axial and proximal motor function (12 items), and distal motor function ( 7 items). Each item is graded from 0 to 3 points. The total score and scores in each domain are given as percentages; the higher the score, the better the motor function.

\section{Study Design}

After acquiring anthropometric, pulmonary function, and respiratory muscle strength data, subjects were assessed on a standard bed at 3 different positions randomized by simple draw to perform the tests at $180^{\circ}, 45^{\circ}$, and $80^{\circ}$ with 10 min rest time between positions. In all positions, OEP data were recorded in 3 phases: phase 1 involved $60 \mathrm{~s}$ of quiet spontaneous breathing; phase 2 involved 2 slow vital capacity maneuvers with $30 \mathrm{~s}$ of quiet spontaneous breathing in between; and phase 3 involved 3 spontaneous cough maneuvers (with the expiratory phase initiated from the highest inspiratory capacity reached) with $30 \mathrm{~s}$ of quiet spontaneous breathing in between (see the figure in the supplementary materials at http://www.rcjournal.com). For each subject, the highest $\mathrm{CPF}$ was considered for data analysis.

\section{Statistical Analysis}

For sample size calculation, CPF was assessed in a pilot study conducted with 4 subjects with DMD (2 subjects were 13 y old, 1 subject was 17 y old, and 1 subject was 20 y old) and 4 age-matched control subjects in all positions. With a $\eta_{\mathrm{p}}{ }^{2}$ of 0.687 , an effect-size $f$ of 1.48 , an alpha error of 0.05 , and a statistical power of $95 \%$, a total sample of 20 individuals (ie, 10 subjects in each group) was estimated.

Data are expressed as mean \pm SD unless otherwise stated. Data normality and distribution were performed using the Shapiro-Wilk test. Intergroup comparisons regarding anthropometric data, lung function, and respiratory muscle strength were performed using the unpaired $t$ test. Intergroup analyses regarding OEP and surface electromyographic data were compared using the Mann-Whitney test, whereas intragroup analyses were performed using the Kruskal-Wallis test with the Dunn post hoc test. Intragroup (r) and intergroup $\left(\varepsilon^{2}\right)$ nonparametric effect sizes were calculated according to Fritz et $\mathrm{al}^{38}$ and Tomczak and Tomczak, ${ }^{39}$ respectively (see supplementary tables at http://www.rcjournal.com). For the former, values were interpreted as small $(<0.10)$, moderate (between 0.10 and 0.30$)$, and large $(>0.50)^{38}$; for the latter, values were interpreted as small $(<0.06)$, moderate (between 0.06 and 0.14$)$, and large $(>0.14) .{ }^{39}$

A significance level of $P<.05$ was adopted. All statistical procedures were performed using Prism 6.0 for Windows (GraphPad, San Diego, California), and the sample calculation and effect sizes were performed using Gpower 3.1.9.2 (Kiel, Germany).

\section{Results}

\section{Sample Characteristics}

Anthropometric data were only statistically different for height $(P=.01)$, which was lower in subjects with DMD when compared to the control group. Predictive and absolute values of lung function and respiratory muscle strength were significantly lower (all $P<.001$ ) in subjects with DMD when compared to controls, except for $\mathrm{FEV}_{1} / \mathrm{FVC}$ ratio. Subjects with DMD had more preserved distal motor function than foot and transfer function, and axial and proximal motor function (Table 1).

\section{Chest Wall Compartmental Volumes and Breathing Pattern}

During quiet spontaneous breathing, subjects with DMD presented lower changes in chest wall tidal volume $(P=$ $.044)$ and lower changes in tidal volume in the rib cage compartment $(P=.025)$ in the supine position and the $45^{\circ}$ position, respectively, compared to controls (Table 2). A 
Table 1. Subject Characteristics

\begin{tabular}{|c|c|c|c|}
\hline & Control Group & Duchenne Group & $P$ \\
\hline Age, y & $15.17 \pm 5.35$ & $15.33 \pm 5.49$ & .99 \\
\hline Height, m & $1.57 \pm 0.16$ & $1.46 \pm 0.14$ & .01 \\
\hline Weight, $\mathrm{kg}$ & $52.44 \pm 2.58$ & $48.58 \pm 16.29$ & .50 \\
\hline Body mass index, $\mathrm{kg} / \mathrm{m}^{2}$ & $20.44 \pm 5.03$ & $22.10 \pm 5.11$ & .61 \\
\hline FVC, L & $3.36 \pm 1.32$ & $1.76 \pm 0.66$ & .001 \\
\hline FVC, $\%$ of predicted & $99 \pm 15.38$ & $60.3 \pm 16.8$ & $<.001$ \\
\hline FVC, $z$ score & $-0.07 \pm 1.20$ & $1.19 \pm 2.42$ & $<.001$ \\
\hline $\mathrm{FEV}_{1}, \mathrm{~L}$ & $2.84 \pm 1.06$ & $1.44 \pm 0.74$ & .001 \\
\hline $\mathrm{FEV}_{1}, \%$ of predicted & $97.8 \pm 14.1$ & $53.4 \pm 17.8$ & $<.001$ \\
\hline $\mathrm{FEV}_{1}, z$ score & $-0.16 \pm 1.20$ & $-3.88 \pm 1.47$ & $<.001$ \\
\hline $\mathrm{FEV}_{1} / \mathrm{FVC}$ & $0.85 \pm 0.07$ & $0.78 \pm 0.16$ & .15 \\
\hline $\mathrm{FEV}_{1} / \mathrm{FVC}, z$ score & $-0.10 \pm 1.40$ & $-3.65 \pm 1.58$ & .23 \\
\hline $\mathrm{FEF}_{25-75 \%}, \mathrm{~L} / \mathrm{s}$ & $3.27 \pm 1.02$ & $1.86 \pm 1.22$ & .006 \\
\hline $\mathrm{FEF}_{25-75 \%}, \%$ & $99.8 \pm 16.7$ & $55.7 \pm 28.7$ & $<.001$ \\
\hline $\mathrm{FEF}_{25-75 \%, z}$ score & $-0.03 \pm 0.74$ & $1.71 \pm .49$ & .002 \\
\hline $\mathrm{P}_{\text {imax }}, \mathrm{cm} \mathrm{H}_{2} \mathrm{O}$ & $111.1 \pm 25.8$ & $59.25 \pm 18.66$ & $<.001$ \\
\hline $\mathrm{P}_{\text {imax }}, \%$ of predicted & $110.4 \pm 26.3$ & $55.5 \pm 17.9$ & $<.001$ \\
\hline $\mathrm{P}_{\mathrm{emax}}, \mathrm{cm} \mathrm{H}_{2} \mathrm{O}$ & $122.4 \pm 31$ & $51.83 \pm 14.70$ & $<.001$ \\
\hline $\mathrm{P}_{\mathrm{emax}}, \%$ of predicted & $114.4 \pm 25.6$ & $44 \pm 12.1$ & $<.001$ \\
\hline $\mathrm{SNIP}, \mathrm{cm} \mathrm{H}_{2} \mathrm{O}$ & $91.83 \pm 13.47$ & $54.3 \pm 15.57$ & $<.001$ \\
\hline SNIP, $\%$ of predicted & $79.2 \pm 13.9$ & $47.7 \pm 15.7$ & $<.001$ \\
\hline Motor function measurement, $\%$ total & NA & $40.25(33.5-82.7)$ & NA \\
\hline Motor function measurement, $\%$ of D1 & NA & $0(0-59.7)$ & NA \\
\hline Motor function measurement, $\%$ of D2 & NA & $55(42.5-98.5)$ & NA \\
\hline Motor function measurement, $\%$ of D3 & NA & $9.3(55.7-100)$ & NA \\
\hline Wheelchair bound & NA & $8(66)$ & NA \\
\hline Noninvasive mechanical ventilation & NA & $3(25)$ & NA \\
\hline Use of cough-assist devices & NA & 0 & NA \\
\hline Steroid treatment & NA & $12(100)$ & NA \\
\hline
\end{tabular}

$\overline{\text { Data are presented as } n}(\%)$, mean $\pm \mathrm{SD}$, or median (interquartile range). Both groups had 12 subjects.

$\mathrm{NA}=$ not applicable; $\mathrm{P}_{\mathrm{imax}}=$ maximum inspiratory pressure; $\mathrm{P}_{\mathrm{emax}}=$ maximum expiratory pressure; $\mathrm{SNIP}=$ sniff nasal inspiratory pressure; $\mathrm{D} 1=$ Domain 1 , standing and transfers; $\mathrm{D} 2=$ Domain 2 , axial and proximal motor function; D3 = Domain 3, distal motor function

higher $\mathrm{f}(P<.001)$, lower $\mathrm{T}_{\mathrm{I}}(P=.03)$, and lower $\mathrm{T}_{\mathrm{E}}$ $(P<.001)$ were observed in all positions in the DMD group compared to the control group. Subjects with DMD also exhibited lower $\mathrm{T}_{\text {tot }}(P=.007)$ and a higher $\mathrm{T}_{\mathrm{I}} / \mathrm{T}_{\text {tot }}$ $(P=.001)$ in the supine position compared to the respective position of the control group (Table 3). The RSBI was higher in subjects with DMD at all positions when compared to controls (Table 3).

Regarding the intragroup analysis, subjects with DMD presented lower changes in tidal volume contribution by the rib cage in supine position $(P<.05)$ and higher changes in tidal volume contribution by the abdomen in the supine and $45^{\circ}$ positions $(P<.05)$ compared to the $80^{\circ}$ position (Table 3$)$. A higher $\mathrm{T}_{\mathrm{I}} / \mathrm{T}_{\text {tot }}(P=.01)$ was also observed in the supine position compared to the $80^{\circ}$ position (Table 3 ).

\section{Cough Peak Flow}

CPF was lower in subjects with DMD when compared to controls in all positions: supine $(P<.001), 45^{\circ}(P=$
$.001)$, and $80^{\circ}(P<.001)$. Regarding intragroup analysis, a lower CPF $(P=.045)$ was observed in subjects with DMD in the supine position when compared to the $80^{\circ}$ position (Fig. 2).

\section{Inspiratory Capacity and Variation in Expiratory Air Volume During Coughing}

The DMD group exhibited lower chest wall inspiratory capacity $(P=.02)$ and rib cage inspiratory capacity $(P=$ $.02)$ in comparison to the control group in all positions. The abdominal inspiratory capacity was also lower in the DMD group at $80^{\circ}(P=.01)$ when compared to controls. Subjects with DMD also exhibited a lower variation in the chest wall expiratory volume during coughing in all positions $(P<.05)$ in the DMD group compared to the respective positions of the control group (Table 2). Regarding intragroup analysis, DMD $(P=.01)$ and controls $(P=.02)$ presented lower rib cage inspiratory capacity in the supine position compared to the $80^{\circ}$ position (Table 2 ). 


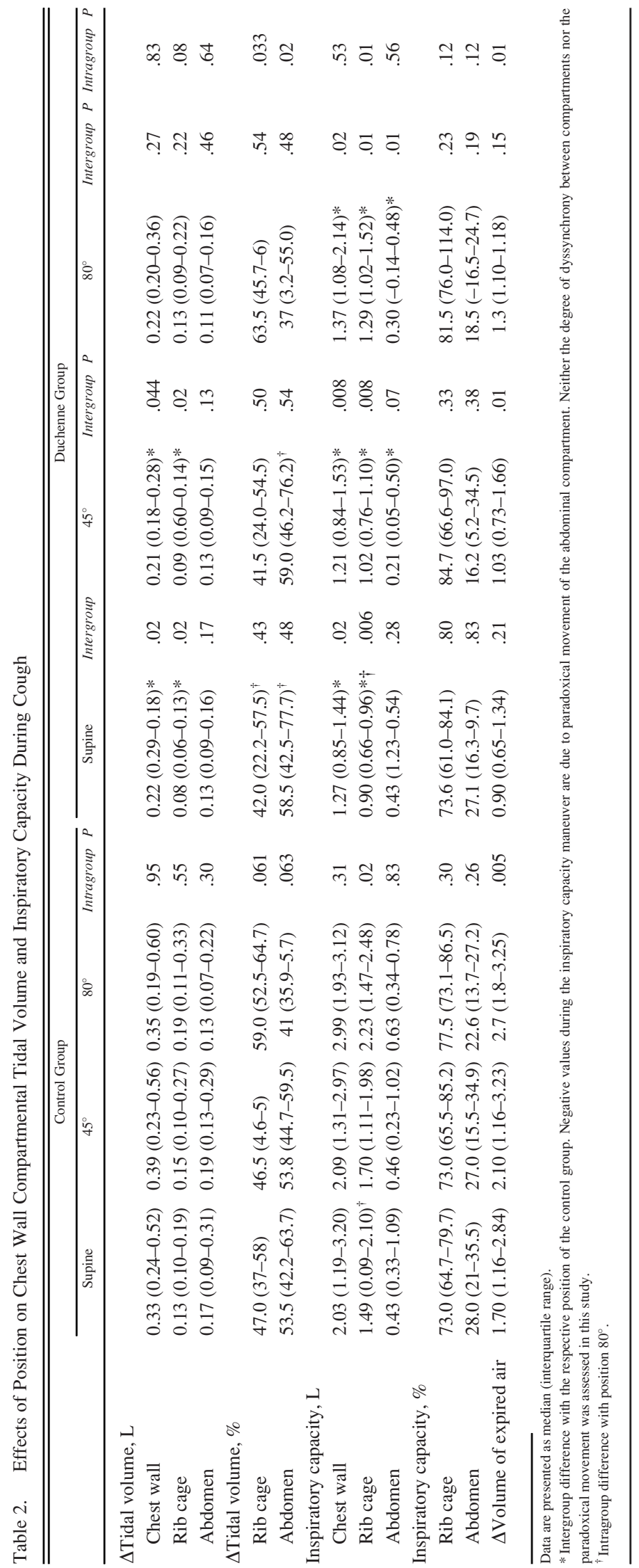

\section{Electromyographic Recordings}

Subjects with DMD exhibited significantly lower inspiratory muscle activation (sternocleidomastoid and scalene) during the inspiratory coughing phase $(P<.05)$ compared to the control group in all positions; the DMD group was more expressive at the $45^{\circ}$ position (Fig. 3). The expiratory muscles were only slightly activated in the subjects with DMD compared to control subjects at $45^{\circ}$ and $80^{\circ}(P<$ $.05)$ for rectus abdominis, and in the supine $(P=$ $.050)$ and $80^{\circ}(P=.001)$ positions for external oblique (Fig. 2). Subjects with DMD presented less muscle activation $(P<.05)$ for all evaluated muscles compared to control subjects during the expiratory coughing phase (Fig. 3). No intragroup differences were observed in both groups during the coughing phases.

\section{Discussion}

To our knowledge, this is the first study to combine the use of OEP to assess voluntary CPF and surface electromyographic activation of the respiratory muscles in subjects with DMD compared to healthy subjects in different positions. The main results of this study were that, when compared to paired healthy subjects, subjects with DMD exhibited higher $\mathrm{CPF}$ at $80^{\circ}$ compared to the supine position and lower $\mathrm{CPF}$ and respiratory muscle activation values in all positions.

Previous studies reported that, in subjects with DMD, breathing pattern and kinematics of the chest wall are influenced by age and disease during spontaneous breathing with a predominance of the thoracic compartment over the abdominal compartment in the supine position., ${ }^{4,13}$ However, this pattern is expected only after $14 \mathrm{y}$ of age. ${ }^{4}$ In healthy subjects, conversely, the contribution of the thoracic compartment is mainly observed in the seated position, whereas the abdominal compartment is observed in the supine position. ${ }^{13}$ In our study, subjects with DMD presented a higher contribution of the abdominal compartment in both supine and $45^{\circ}$ positions, similar to healthy subjects, because only 5 subjects in the DMD group were $>14 \mathrm{y}$ old. However, the absolute abdominal volume in the DMD group was lower compared to the control group.

The supine position imposes mechanical changes on the chest wall, such as cranial diaphragm displacement, expiratory muscle stretching, and reduced lung volume and abdominal 


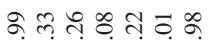

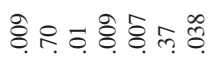

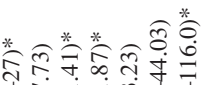

bisid

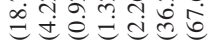

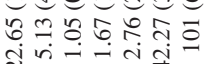

ฮัต

$\checkmark$

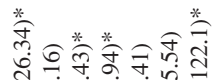

1ㄴ. 워

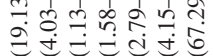

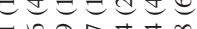

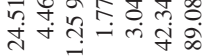

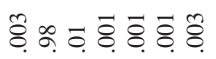

* *** ***

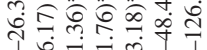

mis

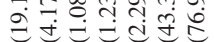

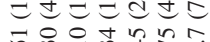

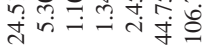

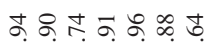

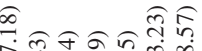

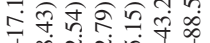

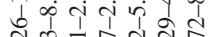

త

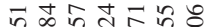

טण-त लंबें

突

竞 $\begin{gathered}\infty \\ \text { i }\end{gathered}$

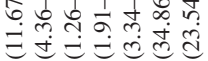

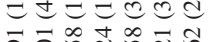

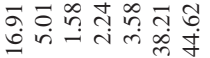

仓ิ

手率

ñ

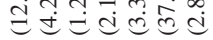

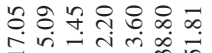

i⿱
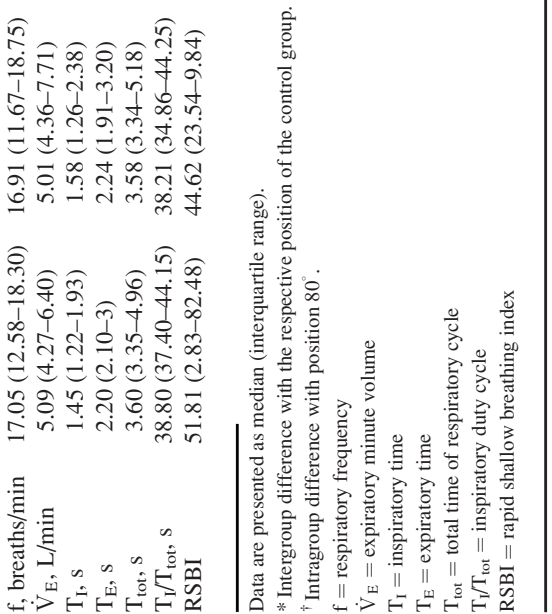

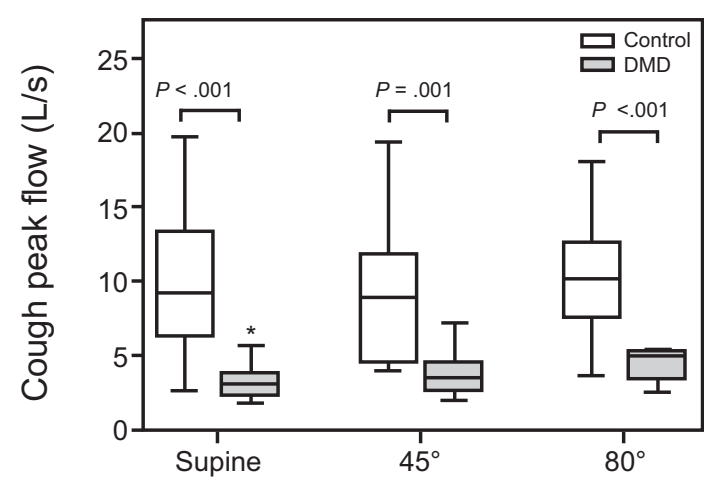

Fig. 2. Box plots showing the effects of positioning on cough peak flow. Center lines indicate the median, and the upper and lower limits of each box represent the 75th and 25th percentiles, respectively. Whiskers denote the minimum and maximum values. $45^{\circ}=$ the supine position with headrest raised at $45^{\circ} ; 80^{\circ}=$ sitting on a stretcher with the headboard raised at $80^{\circ} .{ }^{*} P=.045$, intragroup difference compared with $80^{\circ}$. DMD $=$ Duchenne muscular dystrophy.

compliance, so a higher $\mathrm{CPF}$ in the sitting position would be expected in both groups. ${ }^{40-42}$ However, only the DMD group presented this pattern. Our results suggest that there is an influence of the positioning on CPF generation in DMD, mainly in those with ineffective coughing positioned at $80^{\circ}$ (ie, a $36 \%$ increase in 4 out of 5 subjects with $\mathrm{CPF}<160 \mathrm{~L} / \mathrm{min}$ ). In the control group, CPF did not vary statistically among the positions; this may be explained by previous studies, which reported that, during voluntary coughing in healthy individuals, the associated neural structures can ignore the mechanical changes and increases in lung volume introduced by position, resulting in maximum passive elastic recoil during expiration. ${ }^{43,44}$

The CPF was lower in subjects with DMD compared to healthy subjects in all positions. Different reasons may influence CPF generation in this population, such as changes in the elastic and structural properties of the chest wall, which are characteristics of neuromuscular disease progression. ${ }^{9,10,45,46}$ The disease progression determines the onset of scoliosis, as well as the reduction of lung and chest wall compliance, increasing the mechanical load imposed on respiratory muscles during breathing. ${ }^{10,14,47}$ The inspired volume before coughing may also have played a role in decreasing cough efficiency because it is responsible for (1) stretching the expiratory muscles to an optimum point to increase its contraction efficiency during inspiration and (2) defining the air volume that will be expelled during the expiratory phase. ${ }^{11,48}$ Likewise, this fact may have also contributed to an increase of $25 \%$ of chest wall inspiratory capacity (although not significant) in the CPF generation of subjects with DMD when positioned at $80^{\circ}$. This was due to the increase of the rib cage 

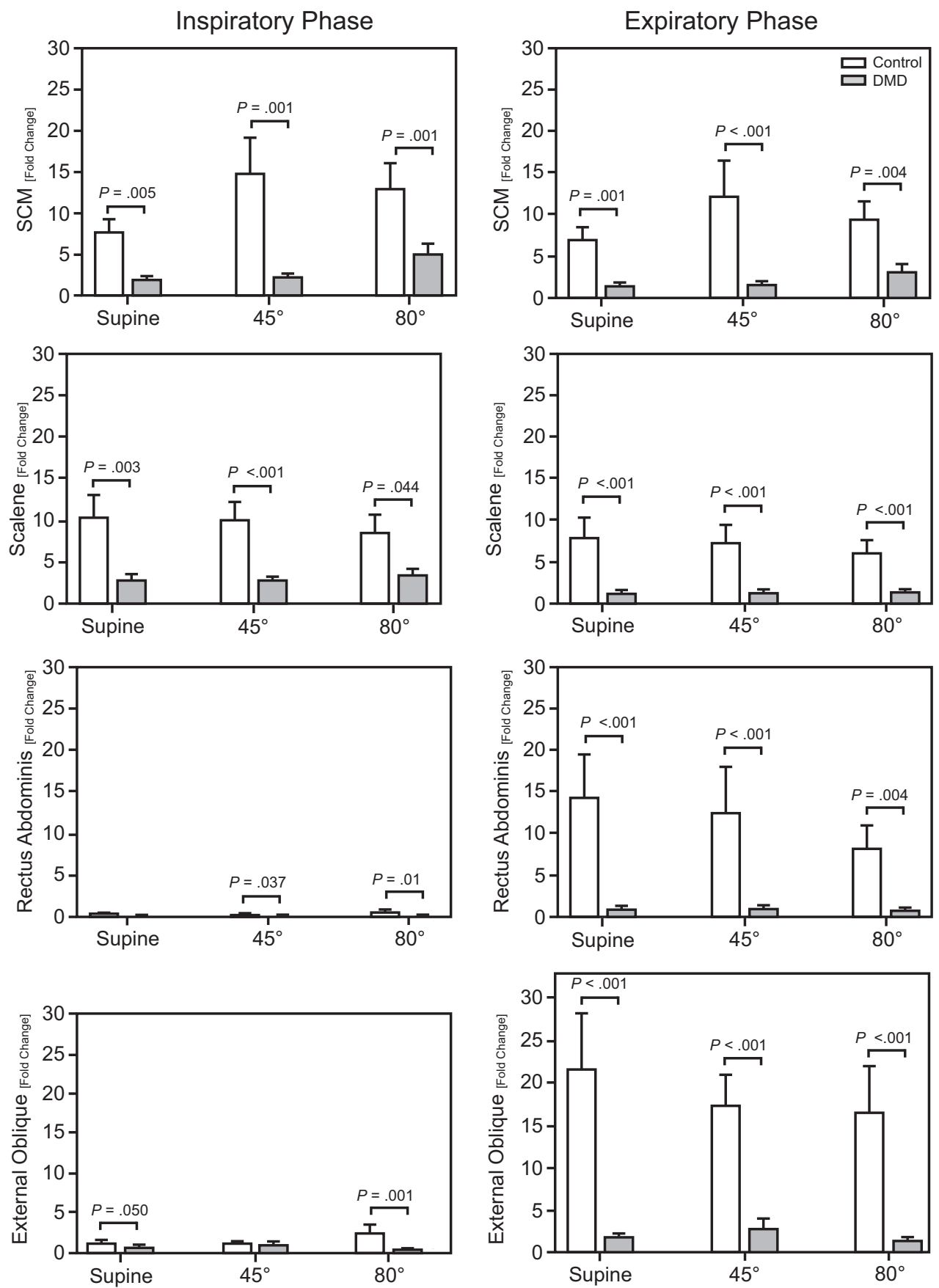

Fig. 3. Muscle activation during the inspiratory and expiratory phases of cough. Data are presented as average and standard error. Fold change (ie, A-B/B) of the electromyographic activation of the sternocleidomastoid muscle. SCM = sternocleidomastoid, DMD = Duchenne muscular dystrophy.

contribution to generate more volume to counterbalance the disadvantages of positioning and diaphragmatic weakness in subjects with DMD. . $^{40,49}$

Our results during quiet spontaneous breathing indicate that subjects with DMD presented lower chest wall tidal volume at the expense of a higher $f$, resulting in a higher RSBI compared with controls, as a strategy to reduce the elastic work within the breath and the perception of dyspnea. ${ }^{10,50}$ Our results agree with those reported by Misuri et $\mathrm{al}^{50}$ who evaluated subjects with neuromuscular disease using a pneumotachograph, including subjects with DMD, and observed that the subjects' ventilatory pattern showed a normal $\dot{\mathrm{V}}_{\mathrm{E}}$, a consistent decrease in $\mathrm{T}_{\mathrm{I}}$ and $\mathrm{T}_{\mathrm{E}}$, and an increase in $\mathrm{f}$ and $\mathrm{RSBI}$. 


\section{EFFECTS OF Positioning IN DMD}

The DMD group exhibited lower muscle activation in all positions compared with healthy subjects. We also observed that the sternocleidomastoid and scalene inspiratory muscles in the control group extended their activation to the expiratory coughing phase. According to previous observations, ${ }^{51-53}$ there is co-activation of the respiratory muscles to control precough inspiratory volume, flow, and pressure and to avoid distortion of the chest wall compartments due to the increased muscular activation during a normal cough maneuver. ${ }^{54}$ In contrast, no co-activation of the inspiratory and expiratory muscles during the 2 phases of coughing was observed in subjects with DMD, probably due to a weakness of the respiratory muscles and consequently low $\mathrm{CPF}$ generation. Future studies could confirm the changes in co-activation of respiratory muscles as a new marker of disease progression.

\section{Study Strengths and Limitations}

To ensure the naturalness of a cough maneuver and to avoid interference (ie, mouthpieces, nose clips, or pneumotachograph) in the regular breathing pattern, we used the OEP system. ${ }^{55}$ We believe that the OEP, which we consider to be a strength of our study, is particularly important to assess $\mathrm{CPF}$ in neuromuscular subjects because they frequently present problems in performing standard spirometric and $\mathrm{P}_{\text {imax }} / \mathrm{P}_{\mathrm{emax}}$ tests due to facial weakness and consequent difficulty in keeping the mouthpiece in place. ${ }^{56}$

Our study is limited by the sample size of subjects, which is related to a limited budget and time constraints. For this reason, subgroup analyses between noninvasive ventilation users and nonusers and between cough-assist device users and nonusers were not available. In addition, we did not evaluate the electromyographic signal of the diaphragm, which is the most responsible for the inspiratory phase of coughing and is likely to be among the most affected by position changes. Moreover, the expiratory activity of the sternocleidomastoid and scalene observed in the control group could represent a tendency to lean the neck forward during cough, rather respiratory compensation. For this reason, we tried to minimize this effect by stabilizing each subject's head and by instructing each subject to avoid flexing the neck during the cough. In addition, we did not evaluate body weight distribution, so we did not quantify the influence of central adiposity on respiratory mechanics.

\section{Conclusions}

In subjects with DMD, positioning influences the generation of CPF with no differences in respiratory muscle activation. When compared to age-matched healthy subjects, subjects with DMD presented lower CPF values and less electromyographic activation during different coughing stages.

\section{REFERENCES}

1. Griggs RC, Bushby K. Continued need for caution in the diagnosis of Duchenne muscular dystrophy. Neurology 2005;64(9):1498-1499.

2. Emery AE. Population frequencies of inherited neuromuscular diseases - a world survey. Neuromuscul Disord 1991;1(1):19-29.

3. Phillips MF, Quinlivan RC, Edwards RH, Calverley PM. Changes in spirometry over time as a prognostic marker in patients with duchenne muscular dystrophy. Am J Respir Crit Care Med 2001;164(12):21912194.

4. LoMauro A, Romei M, Gandossini S, Pascuzzo R, Vantini S, D'Angelo MG, et al. Evolution of respiratory function in Duchenne muscular dystrophy from childhood to adulthood. Eur Respir J 2018;51(2):1701418.

5. Bach JR, Rajaraman R, Ballanger F, Tzeng AC, Ishikawa Y, Kulessa R, Bansal T. Neuromuscular ventilatory insufficiency: effect of home mechanical ventilator use $\mathrm{v}$ oxygen therapy on pneumonia and hospitalization rates. Am J Phys Med Rehabil 1998;77(1):8-19.

6. Bach JR, Ishikawa Y, Kim H. Prevention of pulmonary morbidity for patients with Duchenne muscular dystrophy. Chest 1997;112(4):10241028.

7. Tzeng AC, Bach JR. Prevention of pulmonary morbidity for patients with neuromuscular disease. Chest 2000;118(5):1390-1396.

8. Trebbia G, Lacombe M, Fermanian C, Falaize L, Lejaille M, Louis A, et al. Cough determinants in patients with neuromuscular disease. Respir Physiol Neurobiol 2005;146(2-3):291-300.

9. Kravitz RM. Airway clearance in Duchenne muscular dystrophy. Pediatrics 2009;123(Suppl 4):S231-S235.

10. Lo Mauro A, Aliverti A. Physiology of respiratory disturbances in muscular dystrophies. Breathe (Sheff) 2016;12(4):318-327.

11. Smith JA, Aliverti A, Quaranta M, McGuinness K, Kelsall A, Earis J, Calverley PM. Chest wall dynamics during voluntary and induced cough in healthy volunteers. J Physiol 2012;590(3):563-574.

12. Perrin C, Unterborn JN, Ambrosio CD, Hill NS. Pulmonary complications of chronic neuromuscular diseases and their management. Muscle Nerve 2004;29(1):5-27.

13. Romei M, Mauro AL, D'Angelo MG, Turconi AC, Bresolin N, Pedotti A, Aliverti A. Effects of gender and posture on thoraco-abdominal kinematics during quiet breathing in healthy adults. Respir Physiol Neurobiol 2010;172(3):184-191.

14. LoMauro A, D'Angelo MG, Aliverti A. Assessment and management of respiratory function in patients with Duchenne muscular dystrophy: current and emerging options. Ther Clin Risk Manag 2015;11:1475-1488.

15. American Thoracic Society/European Respiratory Society. ATS/ERS statement on respiratory muscle testing. Am J Respir Crit Care Med 2002;166(4):518-624.

16. Quanjer PH, Stanojevic S, Cole TJ, Baur X, Hall GL, Culver BH, et al. Multi-ethnic reference values for spirometry for the 3-95 yr age range: the global lung function 2012 equations. Eur Respir J 2012;40 (6): 1324-1343.,

17. Sociedade Brasileira de Pneumologia e Tisiologia. Diretrizes Para Testes de Função Pulmonar. J Pneumol 2002;28(3):S155-S165.

18. Ti D S, Fit Ting J-W. Sniff nasal inspiratory pressure: reference values in Caucasian children. Am J Respir Crit Care Med 1999;159(1):107-111.

19. Lanza FC, de Moraes Santos ML, Selman JPR, Silva JC, Marcolin N, Santos J, et al. Reference equation for respiratory pressures in pediatric population: a multicenter study. Plos ONE 2015;10(8):e0135662.

20. Neder JA, Andreoni S, Lerario MC, Nery LE. Reference values for lung function tests. II. Maximal respiratory pressures and voluntary ventilation. Braz J Med Biol Res 1999;32(6):719-727. 


\section{EFFECTS OF Positioning IN DMD}

21. Araújo PR, Resqueti VR, Nascimento-Junior J, Carvalho LdeA, Cavalcanti AG, Silva VC, et al. Reference values for sniff nasal inspiratory pressure in healthy subjects in Brazil: a multicenter study. J Bras Pneumol 2012;38(6):700-707.

22. Massaroni C, Carraro E, Vianello A, Miccinilli S, Morrone M, Levai IK, et al. Optoelectronic plethysmography in clinical practice and research: a review. Respiration 2017;93(5):339-354.

23. Cala SJ, Kenyon CM, Ferrigno G, Carnevali P, Aliverti A, Pedotti A, et al. Chest wall and lung volume estimation by optical reflectance motion analysis. J Appl Physiol 1996;81(6):2680-2689.

24. Lanini B, Bianchi R, Binazzi B, Romagnoli I, Pala F, Gigliotti F, et al. Chest wall kinematics during cough in healthy subjects. Acta Physiol 2007;190(4):351-358.

25. Lanini B, Masolini M, Bianchi R, Binazzi B, Romagnoli I, Gigliotti F, et al. Chest wall kinematics during voluntary cough in neuromuscular patients. Respir Physiol Neurobiol 2008;161(1):62-68.

26. Sarmento A, Resqueti V, Dourado-Júnior M, Saturnino L, Aliverti A, Fregonezi G, et al. Effects of air stacking maneuver on cough peak flow and chest wall compartmental volumes of subjects with amyotrophic lateral sclerosis. Arch Phys Med Rehabil 2017;98(11):2237-2246.

27. Aliverti A, Dellacà R, Pelosi P, Chiumello D, Gatihnoni L, Pedoti A. Compartmental analysis of breathing in the supine and prone positions by optoelectronic plethysmography. Ann Biomed Eng 2001;29(1):60-70.

28. Cesareo A, LoMauro A, Santi M, Biffi E, D’Angelo MG, Aliverti A. Acute effects of mechanical insufflation-exsufflation on the breathing pattern in stable subjects with Duchenne muscular dystrophy. Respir Care 2018;63(8):955-965.

29. Aliverti A, Stevenson N, Dellacà RL, LoMauro A, Pedotti A, Calverley P. Regional chest wall volumes during exercise in chronic obstructive pulmonary disease. Thorax 2004;59(3):210-216.

30. Ward ME, Ward JW, Macklem PT. Analysis of human chest wall motion using a two-compartment rib cage model. J Appl Physiol 1992;72(4):1338-1347.

31. Sarmento A, Fregonezi G, Dourado-Junior MET, Aliverti A, de Andrade AD, Parreira VF, Resqueti V. Thoracoabdominal asynchrony and paradoxical motion in middle stage amyotrophic lateral sclerosis. Respir Physiol Neurobiol 2019;259:16-25.

32. Yang KL, Tobin MJ. A prospective study of indexes predicting the outcome of trials of weaning from mechanical ventilation. $\mathrm{N}$ Engl $\mathrm{J}$ Med 1991;324(21):1445-1450.

33. Hermens HJ, Freriks B, Disselhorst-Klug C, Rau G. Development of recommendations for SEMG sensors and sensor placement procedures. J Electromyogr Kinesiol 2000;10(5):361-374.

34. Evangelista MdeA, Dias FAL, Dourado-Júnior MET, do Nascimento GC, Sarmento A, Gualdi LP, et al. Noninvasive assessment of respiratory muscle strength and activity in myotonic dystrophy. PLoS ONE 2017;12(6): 0177318.

35. Wirth B, Zurfluh S, Müller R. Acute effects of whole-body vibration on trunk muscles in young healthy adults. J Electromyogr Kinesiol 2011;21(3):450-457.

36. Burden A. How should we normalize electromyograms obtained from healthy participants? What we have learned from over 25 years of research. J Electromyogr Kinesiol 2010;20(6):1023-1035.

37. Iwabe C, Miranda-Pfeilsticker B, Nucci A. Medida da função motora: versão da escala para o português e estudo de confiabilidade. Rev Bras Fisioter 2008;12(5):417-424.
38. Fritz CO, Morris PE, Richler JJ. Effect size estimates: current use, calculations, and interpretation. J Exp Psychol Gen 2012;141(1):2-18.

39. Tomczak M, Tomczak E. The need to report effect size estimates revisited. An overview of some recommended measures of effect size. Trends Sport Sci 2014;1(21):19-25.

40. Konno K, Mead J. Static volume-pressure characteristics of the rib cage and abdomen. J Appl Physiol 1968;24(4):544-548.

41. Agostoni E, Rahn H. Abdominal and thoracic pressures at different lung volumes. J Appl Physiol 1960;15:1087-1092.

42. Barnas GM, Green MD, Mackenzie CF, Fletcher SJ, Campbell DN, Runcie C. Effect of posture on lung and regional chest wall mechanics. Anesthesiology 1993;78(2):251-259.

43. Simonyan K, Saad ZS, Loucks TMJ, Poletto CJ, Ludlow CL. Functional neuroanatomy of human voluntary cough and sniff production. Neuroimage 2007;37(2):401-409.

44. Hegland KW, Bolser DC, Davenport PW. Volitional control of reflex cough. J Appl Physiol 2012;113(1):39-46.

45. Estenne M, Heilporn A, Delhez L, Yernault JC, De Troyer A. Chest wall stiffness in patients with chronic respiratory muscle weakness. Am Rev Respir Dis 1983;128(6):1002-1007.

46. Estenne M, Gevenois PA, Kinnear W, Soudon P, Heilporn A, De Troyer A. Lung volume restriction in patients with chronic respiratory muscle weakness: the role of microatelectasis. Thorax 1993;48(7):698-701.

47. Bushby K, Finkel R, Birnkrant DJ, Case LE, Clemens PR, Cripe L, et al. Diagnosis and management of Duchenne muscular dystrophy, part 1: diagnosis, and pharmacological and psychosocial management. Lancet Neurol 2010;9(1):77-93.

48. LoMauro A, Romei M, D’Angelo MG, Aliverti A. Determinants of cough efficiency in Duchenne muscular dystrophy. Pediatr Pulmonol 2014;49(4):357-365.

49. Fayssoil A, Behin A, Ogna A, Mompoint D, Amthor H, Clair B, et al. Diaphragm: pathophysiology and ultrasound imaging in neuromuscular disorders. J Neuromuscul Dis 2018;5(1):1-10.

50. Misuri G, Lanini B, Gigliotti F, Iandelli I, Pizzi A, Bertolini MG, et al. Mechanism of $\mathrm{CO}(2)$ retention in patients with neuromuscular disease. Chest 2000;117(2):447-453.

51. Evangelista LS, Moser D, Dracup K, Doering L, Kobashigawa J. Functional status and perceived control influence quality of life in female heart transplant recipients. J Hear Lung Transpl 2004;23 (3):360-367.

52. Tomori Z, Widdicombe JG. Muscular, bronchomotor and cardiovascular reflexes elicited by mechanical stimulation of the respiratory tract. J Physiol 1969;200(1):25-49.

53. Van Lunteren E, Daniels R, Deal EC, Haxhiu MA. Role of costal and crural diaphragm and parasternal intercostals during coughing in cats. J Appl Physiol 1989;66(1):135-141.

54. Fontana GA, Lavorini F. Cough motor mechanisms. Respir Physiol Neurobiol 2006;152(3):266-281.

55. Weissman C, Askanazi J, Milic-Emili J, Kinney JM. Effect of respiratory apparatus on respiration. J Appl Physiol Respir Environ Exerc Physiol 1984;57(2):475-480.

56. D’Angelo MG, Romei M, Lo Mauro A, Marchi E, Gandossini S, Bonato S, et al. Respiratory pattern in an adult population of dystrophic patients. J Neurol Sci 2011;306(1-2):54-61. 